Article

\title{
Using Radiofrequency Identification Automated Technologies for Predictive Analytics of Signaling Factors to Determining In-Patient Post Treatment of Sleep Quality
}

\author{
Haley Hudson 1, Erick Jones ${ }^{2}$ Dawit Aberra ${ }^{3}$, Shalini Gupta², and Felicia Jefferson ${ }^{1}$ \\ Author Affiliation: 1 Neuroscience and Bioengineering (NeuBE) Lab, Department of Biology, College of Arts and \\ Sciences, Fort Valley State University, Fort Valley, GA 31030, USA. \\ 2 RAID Labs, Department of Industrial, Manufacturing, and Systems Engineering, College of Engineering, University of \\ Texas at Arlington, Arlington, TX 76019, USA. \\ 3 Department of Mathematics and Computer Sciences, College of Arts and Sciences, Fort Valley State University, Fort \\ Valley, GA 31030, USA. \\ * Correspondence: jeffersonf@fvsu.edu; Tel.: 478-827-3254
}

\begin{abstract}
The supply chain has incorporated products by putting them into hair scarfs. This study introduces the use of mini chips in health and beauty products and can reduce fatigue through enhanced sleep patterns. The mini chip could be placed in the scarf and used as a prototype.

This paper presents a new tool known as the scarf prototype which is developed to analyse EMG (electromyogram), ECG (electrocardiography), EEG (electroencephalogram), and EOG (electrooculogram) signals that focuses in the area of sleep disorders. The mini chips used can be used to determine a solution for sleep disruption by using automated analytics. This could lead to improvement in our understanding of sleep disruption and overall sleep physiology. Automated technology allows repeated measurements, evaluation of sleep patterns, and provide suggestions to improve a person's quality of sleep. This analysis compares the use of polysomnography and the scarf prototype. The analytics provide models and shows correlation between variables, such as EMG, ECG, EEG, and EOG. This study shows that the results from the scarf prototype is just as reliable as the original method, polysomnography.
\end{abstract}

Keywords: EMG; EEG; ECG; EOG; Polysomnography

\section{Introduction}

Sleep disorders can cause more detrimental effects on a person's overall health. Symptoms such as low performance level, emotional imbalance, and health ailments all have been attributed primarily to lack of quality sleep. In modern society, sleep has been a standard measure of perfect health because people with good health get a sufficient amount of sleep. Those people who don't get enough sleep, face sleep deprivation issues, that could be treated for major or minor health problems. Sleep deprivation has been negatively related to academic and job performance. (Chiang, 2013) Studies have shown that sleep deprivation has been linked to obesity diabetes, stroke and many other diseases which could lead to death. This is why it is important for adults to get 7-8.5 hours of sleep per day. (Kripke, et all 2002)

The broad impact of this research is consistent and precise sleep disruption that is monitored by developing analytics. There is a provision of daily sleep scores and charts that help the user understand his or her sleep patterns by providing personalized feedback based on the sleep patterns 
with accurate synchronization with smartphone via Automated / RFID technology. The purpose of Radio Frequency Activation technology purpose is used to obtain less expensive cost on wireless devices. (Occhiuzzi et all, 2010) RFID/ Automated technology can provide real life data and solutions to track sleeping patterns such as, how long and deeply an individual rest, how often an individual gets up, and heart and respiration rates. RFID technology provides the supply chain with specific information that is used to identify products and make communication easier. (Muhammad, et all 2013) RFID is used to enhance the way of saving and process data. New technologies in microelectrics and data processing are being developed to enable the use of less expensive components containing RFID. When a RFID chip is installed inside of fabric, it can be used for sorting and tracking the item very quickly. (Nayak, et all, 2015)

There are many wireless technologies including RFID that can provide the wireless platform for sensor networks. These wireless technologies will support wearable equipment and benefit noninvasive monitoring. There has been research on the wireless body area network which is developed to collect a diverse set of data that can be observed from any type of measurements. (Armstrong, 2007) Active RFID tags would allow patients to track their sleep patterns throughout the night. (Swedberg, 2011) Signals from the RFID tags can provide results from monitoring temperature, blood pressure, heartbeat, glucose content and human behavior. (Occhiuzzi et all, 2010) Based on previous studies, EMFs have showed more severe effects on health at night than day time. (Barsam et all, 2012) There has been another technique developed called algorithms, which is an accelerometer used to determine wrist movement. The actigraphy systems are used to monitor sleep in person's environment. The reported accuracies used with actigraphy systems depend on the observed population and the type of sleeping disorder a person is affected with. Patients that have sleep disordered breathing, $80-86 \%$ per-epoch accuracies have been reported. In insomnia patients, $83 \%$ of accuracies have been achieved. This data interpreted can lead to the developments of new sleep medicine research. (O'hare, 2015) Sleeping well is imperative for a healthy body and having a bright mind. However, persistent disturbance can affect our mood, energy level, and capability to face stressful situations. Neglecting sleep may cause serious health ailment, risk of accidents, reduction in productivity, and impaired relationships. To resolve the sleep impairment issue, we need to measure symptoms for the impairment, and sleep patterns. There are also many challenges that affect the use of RFID in the supply chain like business partner's resistance to information sharing. RFID technology always companies to compete with each other globally and provide important business benefits. (Muhammad, et all 2013). The spread of RFID technologies is currently being undertaken now and being used with trading partners in several countries. (Angeles, 2005) The RFID system could be implemented and would take about two to three years for the pay back period. (Karkkaninen, 2003) Many companies are starting to switch over to use the RFID tags over the barcode is due to the many benefits of the tag. One way that the RFID tag is better than the bar code is that these tags can be read within the readers range while with the bar code it requires line of sight to read. Using the RFID tag, the products can include a unique identifier while a bar code doesn't include this information. (McFarlane, et all 2003) Not only can the RFID tag store sleep data, if used in different healthcare facilities, it can store medical information about the patient's personal information and can be stored in the patient's room or mobile device. There are medical transitions like improving RFID and wireless transmitters which gives the patient more freedom to move around their home like the scarf prototype would. (Wang et all, 2013)

\section{Materials and Methods}

In this research, we will attempt to analyze the following Objective, "Evaluating the impacts of sleep disruptions through RFID implementation". We research the main objective by using the following three sub-objectives. Specific objective one is to identify the factors that affect sleep disruptions and evaluate sleep performance in severity. Specific objective two is to determine the 
suitable automated analysis technique to track and monitor sleep disruptions, especially in women. Specific objective three is to evaluate the economics and social impacts of proposed automated analytics.

The proposed research suggests a solution for sleep disruption by using automated/RFID analytics and improves the understanding of sleep disruption physiology. Polysomnography (PSG) employs numerous collections of surface electrodes and measures each physiologic parameters of sleep. To measure all of these parameters, individuals usually spend the night in a sleep laboratory. (Marino et all, 2013) PSG has been known to be expensive and technically complex. (Collop, 2007) As with the scarf prototype, the individual can sleep freely in the comfort of their own homes. Sleep disruption monitoring is gaining attention among sleep monitoring devices that provide the opportunity for tracking sleep disruption consistently. Automated technology records repeated measurements, evaluation of sleep patterns, and suggestions. The facts revealed by clinical and research has a strong standpoint to measure sleep. It records disruption of sleep which is helpful in treating sleep disorders. Moreover, this analysis can also be useful for prescribing individual treatment, and improvised individual health optimization. In fact, some health tracking electronics gadgets assist individuals to track their own sleep performance. Conceptually, the developed analytics provides models and correlation between variables such as EMG, ECG, EOG, and EEG.

The figure below monitors sleep disruption by automated technology.

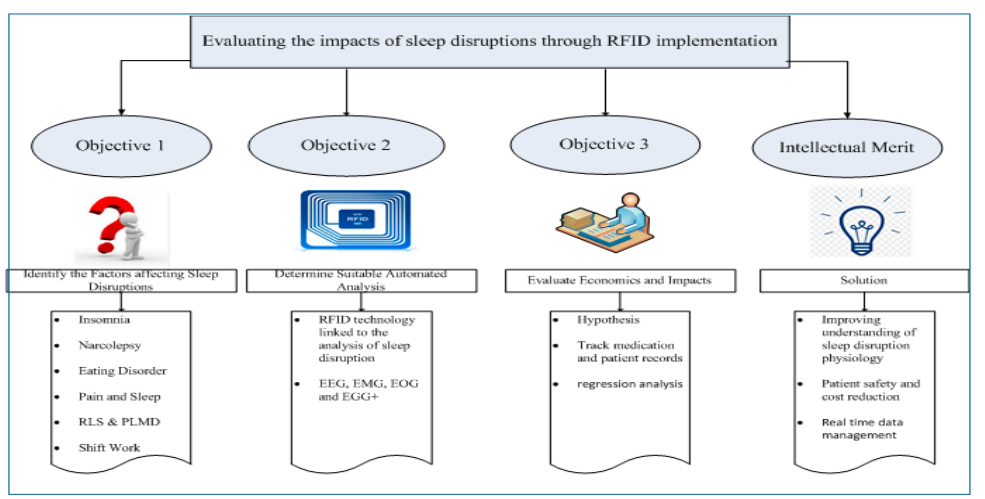

Figure 1

Sleep disruption can be improvised by implementing RFID technology which will track sleep quality, their respective pretreatment, medication, and post treatment. This tracking can be implemented after analyzing EEG, EMG, EOG and ECG electrocardiogram data. data. (Kumar et all, 2010) Sleep disruption can be monitored by developing a sensor and RFID which is an enabled application. Individual records will be stored to reduce the chances of prescribing expensive treatment, which would result into cost saving. Using the comprehensive analysis of EEG, EMG, EOG and ECG signals can be done to track sleep performance.

When creating initial data analytics, we are required to measure 4 types of signals. Firstly, we need to capture EEG signals. This task can be done by using RFID sensor which can be used to measure electrical activities. Since electrical activities measured during the sleep shows different characteristics than the active state, EEG signals reveal different stages of sleep. In the traditional procedures, medical technicians attach electrodes to the head to measure signals. Secondly, we need to measure EMG (electromyography) signals which is used to capture muscle tone activities and shows different records during sleep. A final observation is for EOG (electro-oculography), which 
shows the movement of eye during deep sleep, particularly when we dream. In fact, this aspect helps us understand Rapid Eye Movement (REM). (Mallick, 2011) Conceptually, eyeball movements nature indicates deep sleep. This type of measurement is considered as polysomnography (PSG). The diagram below shows sleep, monitoring research.

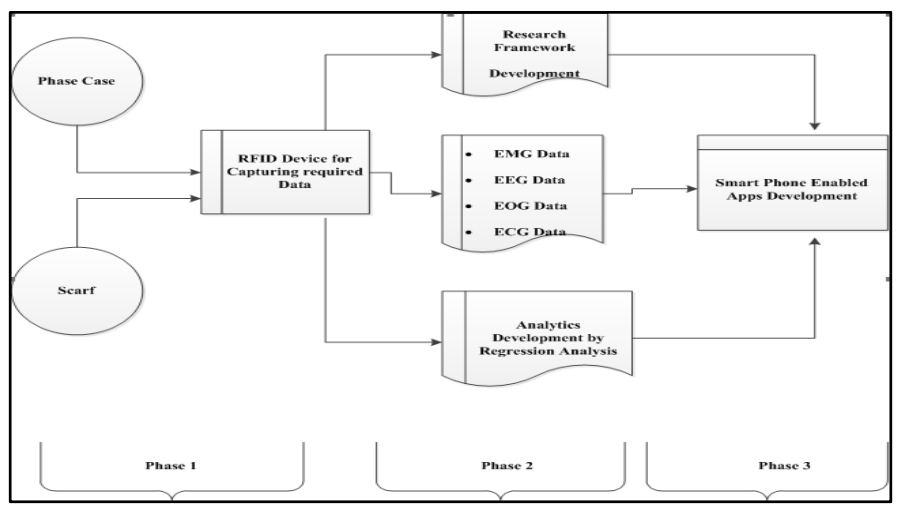

Figure 2

\section{Results}

For this analysis, we have implemented the multiple linear regression. In this procedure, the significant four predictor variables EEG, EMG, ECG, and EOG. were analyzed. This analysis is useful to understand sleep performance. Sample data were created for 18 patients. The analysis was done with four factor variables and one response variable. In this analysis, we will attempt to determine the effects of multiple predictor variables. The response variable is the sleep performance and the four predictor variables are as follows: (1) EEG, (2) EMG and (3) EOG, and (4) ECG. We have assumed 0.01 as the statistical significance level. Initially, we need to check whether the MLR model is suitable for this analysis or not. To understand this, we have performed a preliminary correlation analysis of all three variables for each sleep monitoring method.

We can observe that there is a good correlation between sleep performance and EEG, EMG, and ECG. There is a lower correlation between sleep performance and EOG. In fact, these results could be valuable as they add value to our final model.

\begin{tabular}{|l|l|l|l|l|l|l|}
\hline Variable & N & Mean & Std Dev & Sum & Min. & Max. \\
\hline $\begin{array}{l}\text { Sleep } \\
\text { Performance }\end{array}$ & 18 & 9.069 & 4.237 & 163.250 & 2.500 & 20.000 \\
\hline EEG & 18 & 4.616 & 5.367 & 83.089 & 0.330 & 18.014 \\
\hline EMG & 18 & 2418 & 1573 & 43525 & 500.00 & 5500 \\
\hline EOG & 18 & 20.461 & 21.311 & 368.300 & 1.700 & 90.900 \\
\hline
\end{tabular}




\begin{tabular}{|l|l|l|l|l|l|l|}
\hline ECG & 18 & 0.553 & 0.243 & 9.950 & 0.100 & 0.850 \\
\hline
\end{tabular}

Table 1. Analysis SAS output

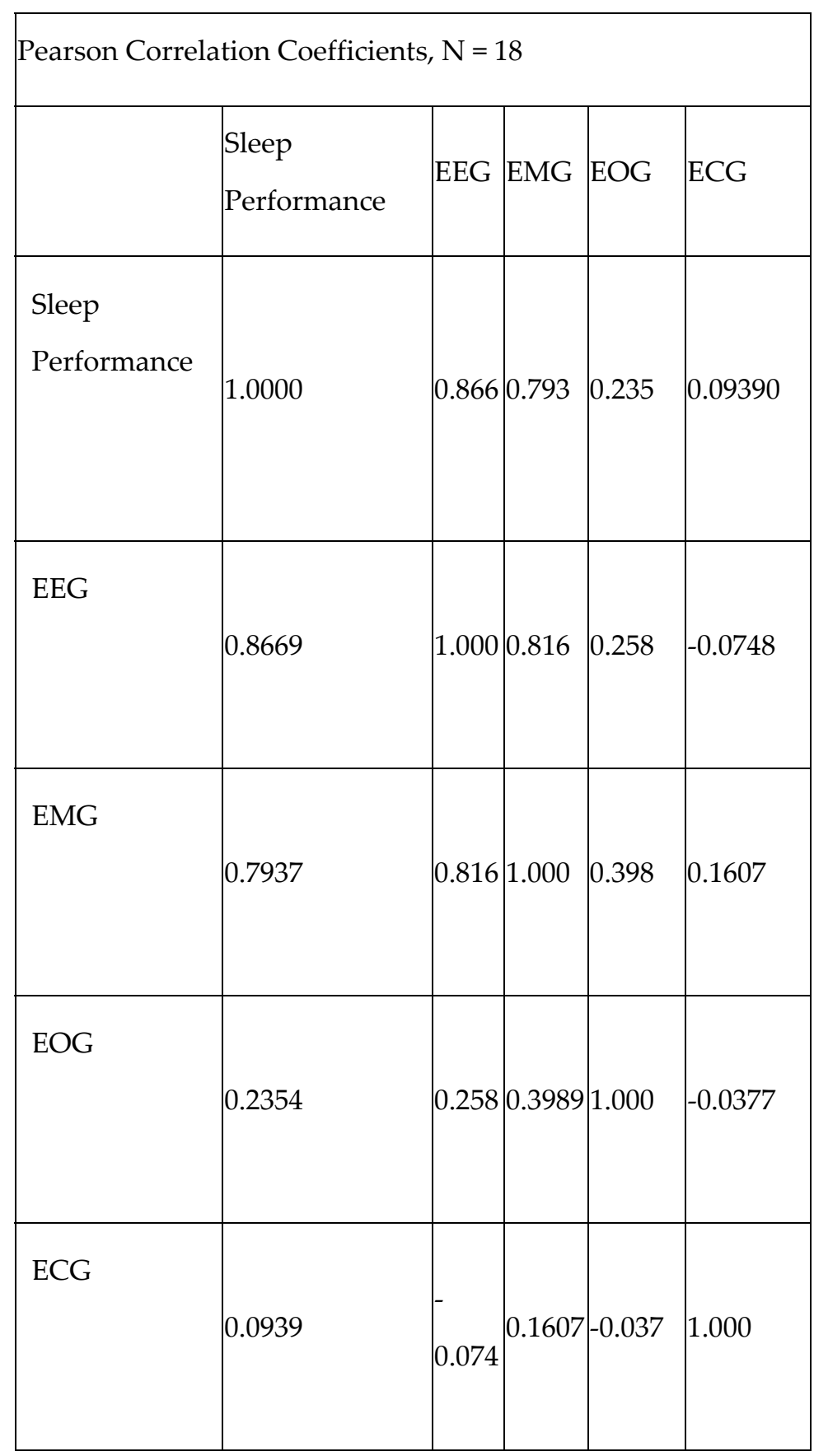

Table 2. Analysis SAS output

Below are the results of a multiple linear regression of the RFID - enabled Sleep disruption monitoring system.

Let, 
$\mathrm{L}=$ Sleep performance

$$
\begin{aligned}
& \mathrm{X} i=\text { Signals } \\
& \mathrm{X} 1=\mathrm{EEG} \\
& \mathrm{X} 2=\mathrm{EMG} \\
& \mathrm{X} 3=\mathrm{EOG} \\
& \mathrm{X} 4=\mathrm{ECG}
\end{aligned}
$$

Regress L vs X1, X2, X3 and X4 to get the P- Values for independent variables X1, X2, X3 and X4. Below is the ANOVA table after the regressing $L$ with $X 1$ and $X 2$. The assumptions for the Preliminary Model have been checked and we found that diagnostics have been performed and

\begin{tabular}{|c|c|c|c|c|c|}
\hline \multicolumn{6}{|c|}{ Analysis of Variance } \\
\hline Source & DF & $\begin{array}{l}\text { Sum of } \\
\text { Squares }\end{array}$ & $\begin{array}{l}\text { Mean } \\
\text { Square }\end{array}$ & F Value & $\operatorname{Pr}>\mathrm{F}$ \\
\hline Model & 4 & 240.03924 & 60.00981 & 11.97 & 0.0003 \\
\hline Error & 13 & 65.18646 & 5.01434 & & \\
\hline Corrected Total & 17 & 305.22569 & & & \\
\hline
\end{tabular}
verified. Hence, we can move forward to develop this model.

The preliminary model is:

$$
\begin{aligned}
& \hat{y}=4.15175+0.57105 X_{1}+0.00052319 X_{2} \\
& +0.00482 X_{3}+2.01762 X_{4} ?
\end{aligned}
$$

(1) 
Table 3. ANOVA Analysis

\begin{tabular}{|l|l|l|l|}
\hline Root MSE & 2.23927 & R-Square & 0.7864 \\
\hline Dependent Mean & 9.06944 & Adj R-Sq & 0.7207 \\
\hline Coeff Var & 24.69030 & & \\
\hline
\end{tabular}

Table 4. ANOVA Analysis

The values in the Correlation Matrix are the values for the Correlations between predictors. We are using 0.70 as our cutoff value for serious multicollinearity. EEG versus ECG are two predictor variables with serious multicollinearity. The value represents the increase in the parameters due to the correlation between the predictors. We will test the significance of the regression as the final test on the preliminary model for $\alpha=0.10$.

$\mathrm{H}_{0}: \mathrm{B}_{\mathrm{k}}=0$ if $\mathrm{F}^{*}>\mathrm{F}(\alpha-1, \mathrm{p}-1, \mathrm{n}-\mathrm{p})$ Reject $\mathrm{H}_{0}$

$\mathrm{H}_{\mathrm{i}}: \mathrm{B}_{\mathrm{k}} \neq 0$

$\mathrm{F}^{*}=\mathrm{MSR} / \mathrm{MSE}=60.00981 / 5.01434=11.9676$

$\mathrm{F}(1-\alpha, 5-1,18-5)=\mathrm{F}(0.90,4,13)=2.44$

$\mathrm{F}^{*}>\mathrm{F}$ therefore we reject $\mathrm{H}_{0}$ and determine the regression is significant. We wanted to create a model that would be easy to use and we believe we have met that requirement. We have created a model which indicates the feasibility of future developments and satisfy requirements. This research shows that it could be considered that the analysis will be useful for creating an RFID enabled sleep monitoring package. 


\section{ROI Results}

- After the initial 1 - year consultation period, stages 1-3 were selected to implement based on budgetary restrictions $\$ 5,000,000$ and interfacing. Table 5 shows the costs and savings associated with this project. Table 6 presents the summary of costs/benefits per project year. Other years project will be evaluated over and the net present value summary will be determined. A required rate of return of seven percent was used in this experiment. Based on the positive net present value, the decision to move forward with the project was projected.

- Additionally, to truly understand the savings, the issue has to be evaluated in subsequent years to gauge the savings to other process improvements. Other factors include long-term profitability and stability of the healthcare organization in the long-term. Although the project is easily justified as-is, there are numerous other savings that are too difficult to evaluate within the scope of this study. RFID can show cost reduction and companies use the ROI to determine whether they want to invest in it. ROI with the use of RFID helps companies save many items each year. There are seven cases that show how the RFID system has benefited a company. For business managers to implement the RFID technologies, they must make the ROI case for RFID, choose the right RFID technology, anticipate RFID problems, manage the IT infrastructure issues and leverage pilot project learning experiences.

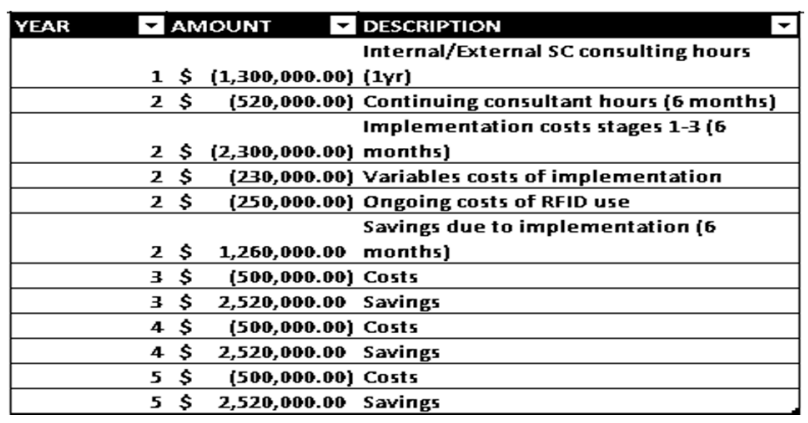

- Table 5: Presented are details of all costs and benefits from project inception to the end of evaluation period.

\begin{tabular}{|c|c|c|c|}
\hline YEAR & & AVINGS (COST) & \\
\hline & $1 \$$ & $(1,300,000.00)$ & \\
\hline & $2 \$$ & $(2,040,000.00)$ & \\
\hline 3 & $\$$ & $2,020,000.00$ & \\
\hline 4 & $4 \$$ & $2,020,000.00$ & \\
\hline & $5 \$$ & $2,020,000.00$ & \\
\hline$=7 \%$ & NF & & $\$ 1,633,433.85$ \\
\hline
\end{tabular}

- Table 6. Presented is a summary of costs/benefits for each year and results for net present value based on a required return of $7 \%$. The NPV $>0$, so this project was worthy. 


\section{Discussion}

Although the study supports major findings, there are some limitations associated with the RFID enabled sleep monitoring system including tracking real time information, data, sleep disruption \& monitoring speed. (Leonard et all, 2006) The integration of ECG, EMG, EOG, EEG and RFID enabled Sleep monitoring system is very helpful when suggesting corrective actions by providing accessibility and data visibility. In fact, sleep disruption can be accurately tracked. Lastly, the RFID implementation acts as a paradigm of technology changeover to the dynamic data flow. Another area that can be focused on in future in order to drive the efficiency of sleep monitoring system is the use of RFID enabled system increase the ability to learn overall sleep performance. These RFID enabled system lead to increasing in overall effectiveness of the health care organization. So, it has been predicted that with the implementation of RFID technology, there can be benefits of increased sleep monitoring quality and accuracy, real-time performance visibility, and faster in recording real time data. These factors can lead to an increase in overall efficiency, quality, and safety. A serious thought can be put into this to evaluate the economic impacts. Despite all the benefits touted for RFID, both within healthcare and other industries, there are many detractors to its implementation.

\section{Conclusions}

The report shows the benefits of RFID implementation with sleep monitoring and its need in the business prospectus of the commercial and hospital industry. There is a vast scope in the use of technology which is used to convert the sleep monitoring into an easier process and money saving technology. RFID is used to improve sleep monitoring service, patient safety, cost reduction, real time data management, in a timely manner and process improvement that can be implemented.

The results obtained by this research suggest the progressive \& beneficial nature of the project in the next five years for the commercial purpose. The suggested analytics offers many reasons to address the challenges confronted by the healthcare organization. By utilizing the advantages of RFID application, there will be a development in economic analysis and application package department. We can recognize this system as a very cost effective tool to monitor sleep performance with points of sale solutions and serve sleep monitoring system globally from anywhere and at the very time. (Ayre, 2012) The analytics developed among four critical factors provides significant insights into how the sleep disruption and the RFID implementation impacts the overall sleep tracking characteristics and the quality of sleep.

\section{References}

[1] The hospital as an enterprise: management strategies. Stefanini, Angelo. 3, 1997, Tropical Medicine and International Health, Vol. 2, pp. 278-283.

[2] Stage implementation of RFID in hospitals. Kumar, Sameer, Livermont, Gregory and McKewan, Gregory. 2010, Technology and Health Care, Vol. 18, pp. 31-46.

[3] Fish, Lynn and Forrest, Wayne. A Worldwide Look at RFID. s.l. : Dow Jones / Factiva.

[4] RFID in the healthcare supply chain: usage and application. Kumar, Sameer, Swanson, Eric and Tran, Thuy. 1, 2009, International Journal of Health Care Quality Assurance, Vol. 22, pp. 67-81.

[5] RFID MEDICINE MANAGEMENT SYSTEM. Shieh, Horng-Lin, Lin, Shih-Fong and Chang, Wen-Sheng. Xian : s.n., 2012. 2012 International Conference on Machine Learning and Cybernetics. pp. 15- 17. 
[6] Measuring the Value of RFID Investment: Focusing on RFID Budget Allocation. Lee, In and Lee, Byoung-Chan. 4, 2012, IEEE TRANSACTIONS ON ENGINEERING MANAGEMENT, Vol. 59, pp. 551-559.

[7] Emerging Technologies in Healthcare: Navigating Risks, Evaluating Rewards. McGrady, Elizabeth, et al. 5, 2010, Journal of Healthcare Management, Vol. 55, pp. 353-365.

[8] RFID and Corporate Responsibility: Hidden Costs in RFID Implementation. Barut, Mehmet, et al. 3, 2006, Business and Society Review, Vol. 111, pp. 287-303.

[9] RFID in the Pharmaceutical Industry: Addressing Counterfeits with Technology. Taylor, Douglas. 141, 2014, Journal of Medical Systems, Vol. 38.

[10] Ayre, Lori. RFID in Libraries: A Step toward Interoperability. 2012.

[11]RFID systems implementation: a comprehensive framework and a case study. Ngai, E.W.T., et al. 9, 2010, International Journal of Production Research, Vol. 48, pp. 2583-2612.

[12] Supply chain replenishment: before-and -after EDI implementation. Leonard, Lori and Davis, Christine. 3, 2006, Supply Chain Management: An International Journal, Vol.11, pp. 225-232.

[16] Carskadon, Mary A., and William C. Dement. "Normal Human Sleep: An Overview." Principles and Practice of Sleep Medicine (2005): 13-23.

[17] Achermann, Peter, and Alexander A. Borbély. "Sleep Homeostasis and Models of Sleep Regulation." Principles and Practice of Sleep Medicine (2011): 431-44.

[18] Kripke DF, Garfinkel L, Wingard DL, Klauber MR, Marler MR Arch Gen Psychiatry. 2002 Feb; 59(2):131-6.

[19] Buysse, Daniel. "Chronic Insomnia." Treatment in Psychiatry. N.p., June 2008. [20] Hered, J. "Genetic Studies in Narcolepsy, a Disorder Affecting REM Sleep." Genetic Studies in Narcolepsy, a Disorder Affecting REM Sleep. N.p., 1999.

[21] Bajraktarov, Stojan et al. "Main Effects of Sleep Disorders Related to Shift Work-opportunities for Preventive Programs." The EPMA Journal 2.4 (2011): 365-370. PMC.

[22] Alan R. Schwartz, Susheel P. Patil, Alison M. Laffan, Vsevolod Polotsky, Hartmut Schneider, and Philip L. Smith "Obesity and Obstructive Sleep Apnea", Proceedings of the American Thoracic Society, Vol. 5, No. 2 (2008), pp. 185-192.

[23] FLORENCE PORTIER, ADRIANA PORTMANN, PIERRE CZERNICHOW, LIONEL VASCAUT, ETIENNE DEVIN, DANIEL BENHAMOU, ANTOINE CUVELIER, and JEAN FRANÇOIS MUIR "Evaluation of Home versus Laboratory Polysomnography in the Diagnosis of Sleep Apnea Syndrome", American Journal of Respiratory and Critical Care Medicine, Vol. 162, No. 3 (2000), pp. 814-818.

[24] Marino, Miguel et al. "Measuring Sleep: Accuracy, Sensitivity, and Specificity of Wrist Actigraphy Compared to Polysomnography." Sleep 36.11 (2013): 1747-1755. PMC.

[25] Naresh M. Punjabi "The Epidemiology of Adult Obstructive Sleep Apnea", Proceedings of the American Thoracic Society, Vol. 5, No. 2 (2008), pp. 136-143. 
[26] Vyas MV, Garg AX, Iansavichus AV, et al. Shift work and vascular events: systematic review and meta-analysis. BMJ 2012; 345: e4800

[27] Garcia-Borreguero, Diego et al.The long-term treatment of restless legs syndrome/Willis-Ekbom disease: evidence-based guidelines and clinical consensus best practice guidance: a report from the International Restless Legs Syndrome Study Group. July, 2013 Sleep Medicine , Volume 14, Issue 7 , $675-684$

[28] Picchietti D; Winkelman JW. Restless Legs Syndrome, Periodic limb movements in sleep, and depression. SLEEP 2005;28(7): 891-898.

[29] Vandrey, Ryan et al. "Interactions between Disordered Sleep, Post-Traumatic Stress Disorder, and Substance Use Disorders." International review of psychiatry (Abingdon, England) 26.2 (2014): 237247. PMC.

[30] Posttraumatic stress disorder in the National Comorbidity Survey. Kessler RC, Sonnega A, Bromet E, Hughes M, Nelson CB Arch Gen Psychiatry. 1995 Dec; 52(12):1048-60.

[31] Sleep disturbances as the hallmark of PTSD: where are we now? Germain Am J Psychiatry. 2013 Apr; 170(4):372-82.

[32] Clinical correlates of poor sleep quality in posttraumatic stress disorder.Germain A, Buysse DJ, Shear MK, Fayyad R, Austin CJ Trauma Stress. 2004 Dec; 17(6):477-84.

[33] Additional categories of sleep-related eating disorders and the current status of treatment.Schenck CH, Hurwitz TD, O'Connor KA, Mahowald MW

Sleep. 1993 Aug; 16(5):457-66.

[34] Longstreth WTJr; Koepsell TD; Ton TG et al. The epidemiology of narcolepsy. SLEEP 2007;30(1):13-26.

[35] Chiang, Yu-Chih, "The effects of sleep on performance of undergraduate students working in the hospitality industry as compared to those who are not working in the industry" (2013). Graduate Theses and Dissertations. Paper 13060.

[36] Swedberg, Claire. "RFID Sensors Track Sleep Patterns." - RFID Journal. N.p., 27 June 2011.

[37] Occhiuzzi, C., and G. Marrocco. "The RFID Technology for Neurosciences: Feasibility of Limbs' Monitoring in Sleep Diseases." IEEE Transactions on Information Technology in Biomedicine IEEE Trans. Inform. Technol. Biomed. 14.1 (2010): 37-43. Jan. 2010.

[38] Collop NA; Anderson WM; Boehlecke B; Claman D; Goldberg R; Gottlieb DJ; Hudgel D; Sateia $\mathrm{M}$; Schwab R. Clinical guidelines for the use of unattended portable monitors in the diagnosis of obstructive sleep apnea in adult patients. J Clin Sleep Med 2007;3(7):737-747.

[39] Drake CL; Roehrs T; Richardson G et al. Shift work sleep dis- order: prevalence and consequences beyond that of symptomatic day workers. SLEEP 2004;27(8):1453-62.

[40] Ralls, Frank M. “Rapid Eye Movement Sleep: Regulation and Function.” Journal of Clinical Sleep Medicine : JCSM : Official Publication of the American Academy of Sleep Medicine 9.6 (2013): 635. PMC.

[41] Abdul Kadar Muhammad Masum Faruk Bhuiyan \& Md. Abul Kalam Azad (2013) Impact of Radio Frequency Identification (RFID) Technology on Supply Chain Efficiency: An Extensive Study 
[42] Armstrong, S. (2007). Wireless connectivity for health and sports monitoring: a review. British journal of sports medicine, 41(5), 285-289.

[43] Wang, L., \& Alexander, C. A. (2013). Telemedicine, Nursing and Medical Management: Applications, Case Studies, and Intelligence from RFID. American Journal of Nursing Research, 1(1), 3442.

[44] Occhiuzzi, C., \& Manocco, G. (2010). The RFID Technology for Neurosciences: Feasibility of Limbs' Monitoring in Sleep Diseases. IEEE Transactions On Information Technology In Biomedicine, 14(1), 37. doi:10.1109/TlTB.2009.2028081

[45] Angeles, Rebecca (2005) ‘Rfid Technologies: Supply- Chain Applications and Implementation Issues', Information Systems Management, 22:1, 51-65

[46] McFarlane, Duncan \& Sheffi, Yossi (2003) "The Impact of Automatic Identification on Supply Chain Operations", The International Journal of Logistics Management, Vol. 14 Iss: 1, pp.1 - 17

[47] Karkkaninen, Mikko(2003) "Increasing efficiency in the supply chain for short shelf life goods using RFID tagging", International Journal of Retail \& Distribution Management, Vol. 31 Iss: 10, pp. $529-536$

[48] Barsam, T., Monazzam, M. R., Haghdoost, A. A., Ghotbi, M. R., \& Dehghan, S. F. (2012). Effect of extremely low frequency electromagnetic field exposure on sleep quality in high voltage substations. Iranian Journal of Environmental Health Science \& Engineering, 9, 1-7.

[49] O'hare, E., Flanagan, D., Penzel, T., Garcia, C., Frohberg, D., \& Heneghan, C. (2015). A comparison of radio-frequency biomotion sensors and actigraphy versus polysomnography for the assessment of sleep in normal subjects. Sleep and Breathing, 19(1), 91-98

[50] Nayak, R., Singh, A., Padhye, R., \& Wang, L. (2015). RFID in textile and clothing manufacturing: Technology and challenges. Fashion and Textiles, 2(1), 1-16.

(C) 2016 by the authors; licensee Preprints, Basel, Switzerland. This article is an open access article distributed under the terms and conditions of the Creative Commons by Attribution (CC-BY) license (http://creativecommons.org/licenses/by/4.0/). 